\title{
Fos and Jun repress transcriptional activation by myogenin and MyoD: the amino terminus of Jun can mediate repression
}

\author{
Li Li, ${ }^{1}$ Jean-Claude Chambard, ${ }^{2}$ Michael Karin, ${ }^{2}$ and Eric N. Olson ${ }^{1,3}$ \\ ${ }^{1}$ Department of Biochemistry and Molecular Biology, The University of Texas M.D. Anderson Cancer Center, Houston, \\ Texas 77030 USA; ${ }^{2}$ Department of Pharmacology, Center for Molecular Genetics, School of Medicine, University of \\ California, San Diego, La Jolla, California 92093 USA
}

\begin{abstract}
Myogenin and MyoD belong to a family of muscle-specific helix-loop-helix (HLH) proteins that have the potential to activate muscle-specific genes in nonmyogenic cells. Peptide growth factors can block the ability of myogenin and MyoD to activate their target genes. Here, we show that the growth factor-inducible proto-oncogenes c-fos, c-jun, and junB mimic the effects of exogenous growth factors and suppress trans-activation of the muscle creatine kinase (MCK) enhancer by myogenin and MyoD. In contrast, JunD, which shares DNA-binding specificity with JunB and c-Jun but is expressed constitutively in muscle cells, is an inefficient inhibitor of the trans-activating capacity of myogenin and MyoD. Transcriptional repression by Fos and Jun is specific to myogenic HLH proteins and is not observed with the widely expressed HLH protein E47, which recognizes the same DNA sequence. Repression of the MCK enhancer by Fos and Jun is targeted at the myogenin and MyoD DNA recognition sequence and can be mediated by the amino terminus of c-Jun. Comparison of several myogenin mutants for their responsiveness to Fos and Jun shows that repression is directed at the basic-HLH region. These results indicate that members of the Jun family can be distinguished on the basis of their effects on muscle-specific transcription and suggest there is cross talk between transcription factors that control myogenesis and those involved in cell proliferation.
\end{abstract}

[Key Words: Myogenin; MyoD; transcriptional activation; myogenesis; HLH proteins]

Received December 20, 1991; revised version accepted February 18, 1992.

Understanding the regulatory networks that link signals at the cell surface to transcriptional responses in the nucleus represents a major challenge of molecular biology. Elucidation of the molecular details of these intracellular pathways requires the identification of specific signaling molecules that act at the cell membrane to initiate a cellular response and the characterization of cisacting DNA sequences and trans-acting factors that serve as nuclear targets for these pathways. Skeletal myoblasts offer an attractive model for studying the mechanisms whereby extracellular signals modulate gene expression because a defined set of polypeptide growth factors has been identified that can block the induction of a battery of genetically unlinked muscle-specific genes (for review, see Florini et al. 1991).

One approach taken to identify intracellular signaling pathways through which growth factors inhibit myogenesis has involved transfection of myoblasts with activated oncogenes whose products are known to transduce

${ }^{3}$ Corresponding author. growth signals from the cell membrane to the nucleus. These studies have revealed that members of the ras family (Olson et al. 1987; Lassar et al. 1989a), as well as certain membrane-associated tyrosine protein kinases (Falcone et al. 1985), can mimic the inhibitory actions of growth factors on the differentiation program. Similarly, forced expression of Fos or Jun, which together comprise the AP-1 complex that confers growth factor responsiveness to several genes (Angel et al. 1987; Bohmann et al. 1987; Chiu et al. 1988), can disrupt myogenesis (Ball et al. 1988; Lassar et al. 1989a; Bengal et al. 1992). Deregulated expression of c- and v-myc also can inhibit muscle-specific gene expression (Falcone et al. 1985; Schneider et al. 1987; Miner and Wold 1991). Many of these oncogene products function in pathways regulated by protein kinase $\mathrm{C}$, which itself can inhibit myogenesis when activated by tumor-promoting phorbol esters (Lin et al. 1987).

Recent studies have revealed a family of muscle-specific nuclear factors that can activate the complete array of skeletal muscle genes when expressed artificially in fibroblasts (for reviews, see Olson 1990; Weintraub et al. 
1991). This family of proteins, which includes MyoD1 (Davis et al. 1987), myogenin (Edmondson and Olson 1989; Wright et al. 1989), myf-5 (Braun et al. 1989), and MRF-4 (Rhodes and Konieczny 1989), shares extensive similarity within a myc homology domain that contains a basic region and a putative helix-loop-helix $(\mathrm{HLH})$ motif, which have been implicated in DNA binding and dimerization (Murre et al. 1989; Davis et al. 1990; Brennan et al. 1991a). Upon heterodimerization with E2A gene products E12 and E47, the myogenic regulatory factors acquire high affinity for the DNA sequence CANNTG, referred to as an E box, which is present in the control regions of numerous muscle-specific genes (Murre et al. 1989; Brennan and Olson 1990; Davis et al. 1990; Chakraborty et al. 1991). The muscle creatine kinase (MCK) gene has been shown to be regulated primarily by a distal upstream enhancer that contains two $\mathrm{E}$ boxes that direct muscle-specific transcription through interaction with myogenic HLH proteins (Lassar et al. 1989b; Brennan and Olson 1990).

There is an intriguing antagonism between the actions of myogenic HLH proteins and signals generated by growth factors. Expression of MyoD at high levels, for example, can suppress cell proliferation and activate muscle-specific genes, even in the presence of growth factors or activated oncogenes that would normally inhibit myogenesis (Davis et al. 1987; Crescenzi et al. 1990; Sorrentino et al. 1990). Conversely, high concentrations of fibroblast growth factor (FGF), transforming growth factor- $\beta$ (TGF- $\beta$ ), or fetal bovine serum can override the actions of $\mathrm{MyOD}$ and myogenin and repress the ability of these proteins to activate muscle-specific genes (Davis et al. 1987; Vaidya et al. 1989; Brennan et al. $199 \mathrm{lb}$ and references therein). Negative regulation of MyoD function is also apparent during myogenesis, when the MyoD protein is expressed constitutively in proliferating myoblasts prior to initiation of differentiation, and becomes "activated" upon withdrawal of exogenous growth factors (Davis et al. 1987). These observations suggest that there is a convergence of growth factor-signaling pathways and pathways controlled by members of the MyoD family and that the decision of a myoblast to differentiate or divide is dictated by a balance between these antagonistic programs. Little is known, however, of the mechanisms whereby growth factor and oncogenic pathways suppress the activities of myogenic HLH proteins.

The availability of cloned regulatory factors that can directly activate muscle-specific genes through interaction with defined DNA sequences offers an opportunity to dissect the mechanisms whereby growth factor and oncogenic signals block muscle-specific transcription. In this study we used the 5'-flanking region of the MCK gene as a target to investigate whether members of the Fos and Jun families of growth factor-inducible early genes can substitute for exogenous growth factors and block the actions of myogenin and MyoD. We show that Fos and Jun can specifically repress transcriptional activation by myogenic HLH proteins and that the amino terminus of c-Jun is important for efficient repression.
Our findings demonstrate that there is cross talk between myogenic $\mathrm{HLH}$ proteins and transcription factors that positively regulate cell growth and provide evidence for a pathway through which members of the Fos and Jun families can repress muscle-specific gene expression.

\section{Results}

Fos blocks myogenin- and MyoD-dependent activation of MCK control sequences

To analyze for possible regulatory interactions between myogenin and various growth factor-inducible early gene products, we used muscle-specific regulatory sequences from mck linked to a chloramphenicol acetyltransferase (CAT) reporter gene. Induction of mck is dependent on a muscle-specific enhancer that lies between -1350 and -1048 relative to the transcription initiation site (Jaynes et al. 1988; Sternberg et al. 1988). This enhancer contains a high-affinity binding site for myogenin and MyoD that is essential for muscle specificity and trans-activation by these myogenic regulatory factors (Buskin and Hauschka 1989; Lassar et al. 1989b; Brennan and Olson 1990). The chimeric reporter gene $\mathrm{MCK}-\mathrm{CAT}$, which contains the 246-bp MCK promoter fused immediately upstream of CAT and the 302-bp enhancer inserted $3^{\prime}$ of CAT, is strictly muscle specific (Sternberg et al. 1988) and was used in initial experiments.

Figure 1A shows that MCK-CAT is not expressed in $10 \mathrm{~T} 1 / 2$ cells when transfected alone but can be activated efficiently by cotransfection with a myogenin expression vector (cf. lanes 1,2). Responsiveness to myogenin is de-

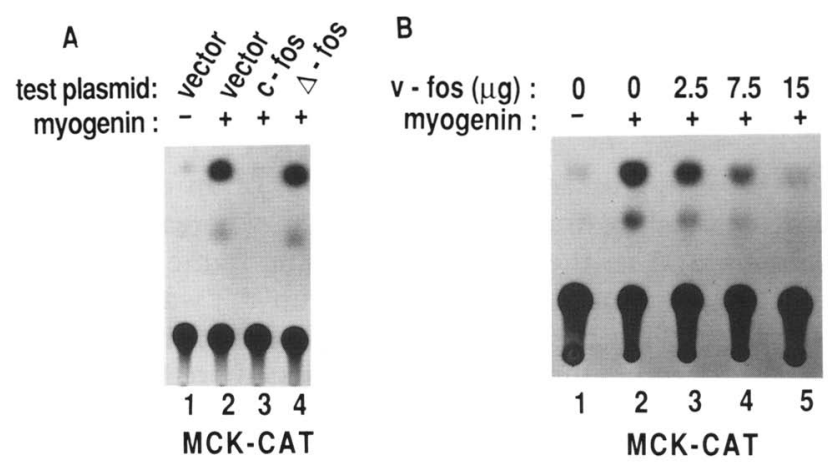

Figure 1. v- and c-Fos block trans-activation of MCK-CAT by myogenin. 10T1/2 cells were transiently transfected with MCK-CAT $(5 \mu \mathrm{g})$ and EMSV-myogenin, as indicated. Expression vectors encoding $\mathrm{v}$-Fos, $\mathrm{c}$-Fos, and the c-Fos frameshift mutant $\Delta$-Fos were included in the transfections, as specified. Twenty-four hours after transfection, cultures were transferred from GM to DM and CAT activity was assayed in cell extracts $48 \mathrm{hr}$ later. $(A)$ Transfections with $5 \mu \mathrm{g}$ of EMSV-myogenin $(+)$ or EMSV lacking an insert $(-)$ and $7.5 \mu \mathrm{g}$ of c-Fos, $\Delta$-Fos, or the RSV-LTR expression vector lacking an insert (vector), as indicated. $(B)$ Transfections with the indicated amounts of $v$-Fos and $5 \mu \mathrm{g}$ of EMSV-myogenin (+) or EMSV lacking an insert (-). All experiments were performed at least three times with comparable results. 
pendent on the MCK enhancer and is not observed with the MCK promoter alone, under the conditions of these assays (Edmondson and Olson 1989). When transfection assays were performed in the presence of the c-Fos expression vector, trans-activation of MCK-CAT by myogenin was suppressed. This suppression was not observed using a frameshift mutant of c-Fos $(\Delta$-Fos) that is biologically inactive (Fig. 1A). The lack of repression by the $\Delta$-fos plasmid shows that the c-Fos expression vehicle does not repress MCK-CAT by competing for limiting transcription factors. v-Fos, encoded by the vector FBJ-fos (van Beveren et al. 1983), was also able to block trans-activation of MCK-CAT by myogenin; the extent of suppression was dependent on the relative ratios of myogenin and v-Fos expression vectors (Fig. 1B). Suppression of MCK-CAT by $\mathrm{v}$ - and c-Fos also did not reflect a generalized effect on transcription, as Rous sarcoma virus (RSV)-CAT, which contains the constitutively active RSV promoter and enhancer, was not suppressed by cotransfection with the Fos expression vectors (data not shown). In addition, the reporter -73Col-CAT, which contains the AP-1 responsive collagenase promoter (Angel et al. 1987), is activated by c-Fos (data not shown). To rule out the possibility that $\mathrm{v}$-Fos and c-Fos indirectly prevented activation of MCKCAT by inhibiting myogenin expression from the Maloney sarcoma virus long terminal repeat (MSV-LTR) in the EMSV-myogenin expression vector, we measured myogenin mRNA expression in transiently transfected cells by Northern analysis and found it to be unaffected in the presence of cotransfected plasmids /data not shown).

\section{Myogenic HLH proteins can discriminate between different members of the Iun family}

We also investigated whether members of the iun family of oncogenes influenced the actions of myogenin. Figure 2 shows that trans-activation of $\mathrm{MCK}-\mathrm{CAT}$ by myogenin was suppressed by cotransfection of an expression vector encoding JunB, c-Jun, and v-Jun, whereas a frameshift mutant in the $c$-Jun open reading frame that does not encode a functional protein (c-Jun ${ }^{\text {mut }}$ ) was without effect. As with the Fos expression vectors, the Jun expression vectors did not inhibit expression of RSV-CAT or expression of myogenin driven by the MSV-LTR/data not shown).

In contrast to the jun $B$ and c-jun genes, which are expressed at a basal level in differentiated myocytes and are rapidly up-regulated by growth factors that inhibit myogenesis, the jun $D$ gene is expressed at high levels in muscle cells, as well as other types, and is not regulated during differentiation (Ryder et al. 1989; Li et al. 1990). We therefore examined the specificity of trans-repression using an expression vector encoding JunD. As shown in Figure 2, JunD failed to block activation of MCK-CAT by myogenin. At the plasmid ratios used in these experiments, we observed reproducibly a stimulation of MCK-CAT of $\sim 1.5$ - to 2-fold by JunD. Because all of the Jun cDNAs were contained in the same expression

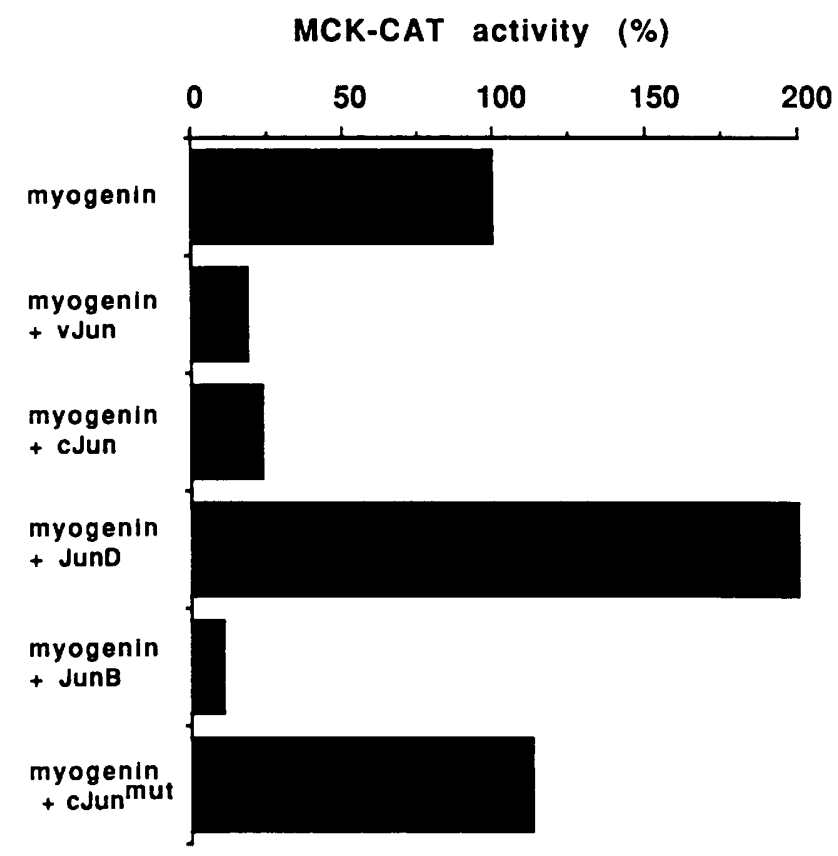

Figure 2. JunB, c-Jun, and v-Jun block trans-activation of MCK-CAT by myogenin. 10T1/2 cells were transfected transiently with MCK-CAT ( $5 \mu \mathrm{g})$ and EMSV-myogenin $(5 \mu \mathrm{g})$. Ten micrograms of expression vectors encoding $\mathrm{v}$-Jun, JunB, c-Jun, JunD, and mutant c-Jun cDNAs under control of the RSV-LTR was included, as specified. Twenty-four hours after transfection, cultures were transferred from GM to DM and CAT activity was assayed in cell extracts $48 \mathrm{hr}$ later. Values are expressed relative to the level of CAT activity in cultures transfected with MCK-CAT, EMSV-myogenin, and the RSV-LTR expression vector lacking an insert. A representative experiment is shown. Comparable results were obtained in at least three separate experiments.

vector and radioimmunoprecipitation indicates that they led to synthesis of similar amounts of protein in F9 cells (T. Smeal, unpubl.), these results suggest that the actions of JunB and c-Jun are distinct from those of JunD.

To determine whether sensitivity to repression by Fos and Jun was a general property of myogenic HLH proteins, we examined whether Fos and Jun proteins were able to repress activation of MCK-CAT by MyoD. As reported previously (Lassar et al. 1989a), c-Fos was a potent repressor of MyoD activity (Fig. 3A). v-Jun was also an efficient repressor of $\mathrm{MyoD}$, whereas c-Jun was relatively less effective. Nearly complete inhibition by c-Jun was achieved, however, when higher amounts of the expression vector were used (data not shown). The combination of c-Jun $+\mathrm{c}$-Fos resulted in repression to a level similar to that observed with c-Fos alone (Fig. 3A). We also investigated whether increasing the level of MyoD could overcome inhibition by Fos and Jun. As shown in Figure 3B, increasing the amount of cotransfected MyoD could partially overcome the inhibition by c-Fos and $v$-Jun. These results suggest that muscle-specific gene activation is determined by the ratio of MyoD or myogenin to Fos or Jun. 


\section{A}

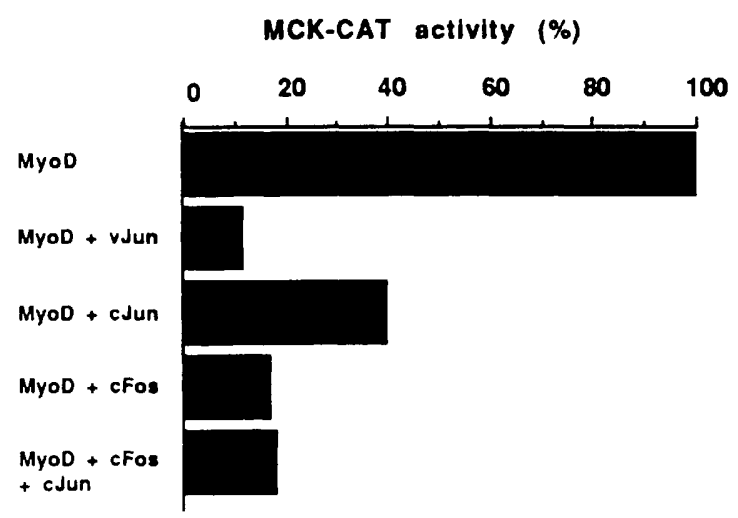

B

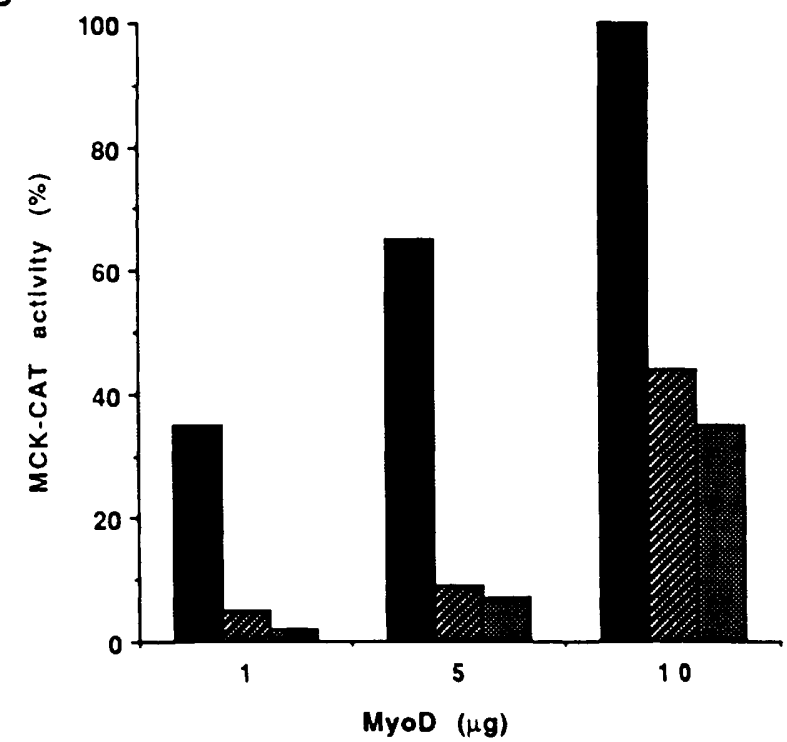

Figure 3. Inhibition of MyoD activity by Fos and Jun. $|A|$ $10 \mathrm{~T} 1 / 2$ cells were transfected transiently with MCK-CAT 14 $\mu \mathrm{g})$ and EMSV-MyoD $(5 \mu \mathrm{g})$, as indicated. Fos and Jun cDNAs (1 $\mu g$ ) were under transcriptional control of the RSV-LTR so that their relative potencies could be compared directly. Values are expressed relative to the level of CAT activity in cultures transfected with MCK-CAT, EMSV-MyoD, and the RSV-LTR expression vector lacking an insert. $(B)$ 10T1/2 cells were transfected transiently with MCK-CAT $(4 \mu \mathrm{g})$. Expression vectors encoding c-Fos and v-Jun, under control of the RSV-LTR, and EMSV-MyoD were included in transfections in the amounts indicated. Values for MCK-CAT expression are expressed relative to the maximal level with $10 \mu \mathrm{g}$ of EMSV-MyoD. (Solid bars) control; (hatched bars) +c-Fos, $5 \mu \mathrm{g}$; (stripped bars) + vJun, $1.0 \mu \mathrm{g}$. The results shown represent the average values for three experiments.

Trans-activation by E2-5 is unaffected by c-Fos and v-Iun

Activation of muscle-specific transcription by myogenin and MyoD requires hetero-oligomerization with E2A products, such as E12 and E47 (Lassar et al. 1991). Repression of the activity of myogenin and MyoD by Fos and Jun could formally be mediated indirectly by inhibiting the activity of E2A products. To investigate whether Fos and Jun affected the activity of E2A products, we tested the ability of E47, also called E2-5, to trans-activate a reporter gene linked to a multimerized $\mathrm{E}$ box that serves as the target sequence for E47. The reporter gene used for these experiments, $(E 2+5)_{4}$ TATA-CAT, contains four copies of the $\mu \mathrm{E} 2$ and $\mu \mathrm{E} 5 \mathrm{E}$ boxes upstream of a basal promoter and is strongly transactivated by E47 (Henthorn et al. 1990). As shown in Figure 4, this target gene showed low activity in 10T1/2 cells, presumably owing to low-level expression of endogenous E2A products. However, when cotransfected with an E47 (E2-5) expression vector, high levels of expression of the reporter gene were observed. Neither $\mathrm{v}$-Fos nor c-Jun significantly diminished the level of trans-activation of the reporter gene by E2-5. The v-Fos and c-Jun expression vectors also had no effect on expression of the reporter gene in the absence of E2-5/data not shown). It is conceivable that higher concentrations of Fos or Jun might repress trans-activation by E2-5, but the apparent lack of sensitivity of E2-5 to repression at concentrations of the Fos and Jun expression vectors that extinguish activation by myogenin and MyoD argues against a role for E2-5 as a target for repression. These results suggest, therefore, that repression by Fos and Jun is targeted specifically at myogenic HLH proteins.

\section{A}

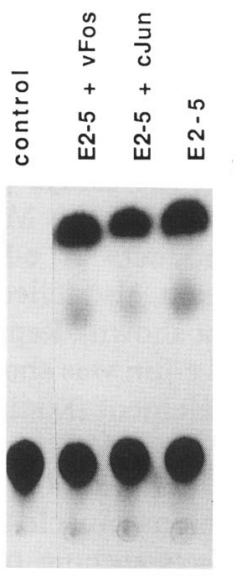

B

$\left(\right.$ E2+5) ${ }_{4}$-TATA-CAT

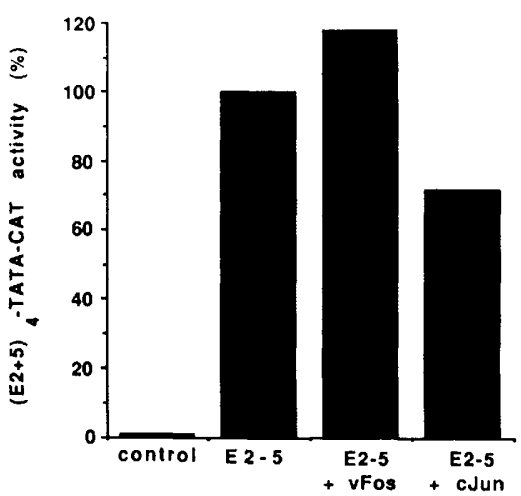

Figure 4. v-Fos and c-Jun do not repress trans-activation by E2-5. 10T1/2 cells were transiently transfected with $5 \mu \mathrm{g}$ of pSVE2-5, $5 \mu \mathrm{g}$ of $(\mathrm{E} 2+5)_{4}-\mathrm{TATA}-\mathrm{CAT}$, and $10 \mu \mathrm{g}$ of expression vectors encoding $\mathbf{v}$-Fos or $\mathrm{c}$-Jun or an expression vector lacking a cDNA insert (control), as indicated. Twenty-four hours after transfection, cultures were transferred from GM to DM and CAT activity was assayed in cell extracts $48 \mathrm{hr}$ later. $(A)$ A representative CAT assay is shown; $(B)$ the average results from three independent experiments are shown. Values are expressed relative to the level of CAT activity in cultures transfected with pSVE2-5, the reporter gene, and the RSV-LTR expression vector lacking an insert. 
Li et al.

The MCK enhancer is repressed by Fos and Jun through the $E$ box in the enhancer core

Suppression of MCK-CAT by Fos and Jun could, in principle, be mediated by the MCK promoter or the enhancer. To determine whether the enhancer was the target for trans-repression, we used a reporter gene, pSVCATCKe, in which the 302-bp MCK enhancer $(-1350 /-1048)$ was combined with the SV40 promoter, which is active in $10 \mathrm{~T} 1 / 2$ cells. Figure $5 \mathrm{~A}$ shows that this reporter gene could be trans-activated by myogenin and that trans-activation was suppressed by v-Fos, JunB, or v-Jun. The ability of myogenin to trans-activate this reporter plasmid agrees with previous studies in which the MCK enhancer was defined as a target for myogenindependent activation (Edmondson and Olson 1989). To exclude the possibility that repression of pSVCATCKe might be mediated by the SV40 promoter, pSV2CAT, which contains the SV40 promoter and enhancer, was used in transfection assays. Consistent with previous observations (Edmondson and Olson 1989), myogenin trans-activated this reporter weakly. This is probably the result of the presence of two $E$ box sequences within the SV40 promoter (Tooze 1981). Trans-activation of pSV2CAT by myogenin was reduced in the presence of v-Fos and JunB, but the basal activity of the reporter was not suppressed, indicating that v-Fos and JunB did not repress the SV40 promoter. v-Fos, v-Jun, and JunB also did not repress activity of pSV2CAT in the absence of myogenin (Angel et al. 1988, and data not shown).

Fos and Jun regulate transcription of a variety of genes through interaction with a DNA sequence known as an AP-1 site, TGAG/CTCA (Angel et al. 1987, 1988b; Bohmann et al. 1987; Lee et al. 1987; Piette and Yaniv 1987; Chiu et al. 1988). There are no AP-1 sites within the MCK enhancer that could serve as potential targets for binding of Fos/Jun. Gel mobility-shift assays performed with DNA fragments encompassing the MCK enhancer and in vitro translation products of c-Fos, c-Jun, and JunB, alone and in combination, also failed to reveal measurable interactions (data not shown). Repression of the c-fos promoter by c-Fos and c-Jun was shown to be mediated by the serum response element (Konig et al. 1989), which is closely related to the CArG motif, $\mathrm{CC}(\mathrm{A} / \mathrm{T})_{6} \mathrm{GG}$ (Minty and Kedes 1986). CArG motifs are present in the control regions of numerous muscle-specific genes and are important for muscle-specific transcription (Minty and Kedes 1986); a CArG motif is present at $-1234 /-1224$ in the MCK enhancer (Sternberg et al. 1988). To assess the role of this site in mediating trans-repression, we created a mutation at that site and left the remainder of the 302-bp enhancer intact (mutant CArG; Fig. 5B). In addition, we tested a deletion mutant containing the $3^{\prime}$ half of the enhancer $(-1204 /$ -1048 , mutant e6; Fig. 5B), which lacks the CArG motif, for responsiveness to v-Fos, JunB, or v-Jun. Both enhancer mutants were activated by myogenin and repressed by v-Fos and JunB, indicating that the CArG motif does not mediate trans-repression and the elements involved in activation and repression map to the region between -1204 and -1048 . It is noteworthy that deletion mutant e6 also removes a perfect AP-2 site $(-1216 /-1209)$, which has been shown to mediate the actions of growth factor signals on a variety of genes (Imagawa et al. 1987).

Activation of the MCK enhancer involves cooperative interactions among myogenic $\mathrm{HLH}$ proteins that bind to an E box referred to as the MEF-1 site (Buskin and Hauschka 1989) and other enhancer-binding factors that bind to surrounding sites (Gossett et al. 1989; P. Cserjesi, B. Lilly, and E. Olson, unpubl.). To determine whether trans-repression is mediated through the MEF-1 site, we tested whether v-Fos, JunB, and v-Jun block trans-activation of the (MEF-1) ${ }_{4}$-tkCAT reporter, which contains four MEF-1 sites upstream to the thymidine kinase basal promoter. Trans-activation of the thymidine kinase promoter in this reporter plasmid by MyoD requires a minimum of two MEF-1 sites (Weintraub et al. 1990). As shown in Figure 5C, myogenin strongly trans-activated this reporter in 10T1/2 cells, and v-Fos, JunB, and v-Jun inhibited trans-activation. Repression of $(\mathrm{MEF}-1)_{4}-$ tkCAT by Fos and Jun was dependent on the MEF-1 sites, and myogenin and was not observed with tkCAT lacking these sites. Repression is therefore targeted at the MEF-1 sites and is not mediated indirectly by the thymidine kinase promoter (Fig. 5C; see also Angel et al. 1988a; Yang-Yen et al. 1990).

\section{The amino terminus c-Jun mediates repression}

To determine which regions of c-Jun are important for inhibition of myogenin and MyoD activity, we examined the ability of several deletion derivatives of c-Jun to repress trans-activation of MCK-CAT. As shown in Figure $6 \mathrm{~A}$, deletion of amino acids $1-87$ or 6-223 from c-Jun resulted in a large decrease in its ability to repress myogenic activity. These regions of c-Jun encompass the transcriptional activation domains (Angel et al. 1989). Previous transfection experiments indicate that c-Jun $\Delta 1$ 87 , and c-Jun $\Delta 6-223$ are stable nuclear proteins that accumulate in amounts similar to the wild-type c-Jun protein (Angel et al. 1989). Dimerization does not appear to be essential for repression because a c-Jun mutant that lacks the leucine zipper (c-Jun $\Delta$ LZ) (Schule et al. 1990) also showed inhibitory activity. The leucine zipper does appear to contribute to repression, however, because c-Jun $\Delta L Z$ was a less potent inhibitor than wild-type c-Jun. Because there is a delicate balance between the amount of myogenic regulator and c-Jun needed for repression, and we have only measured potential repression of myogenin and MyoD by c-Jun mutants at a single ratio of expression vectors, we cannot rule out the possibility that mutants with diminished inhibitory activity might fully repress muscle transcription at higher concentrations.

To further investigate the repression mediated by the amino terminus of c-Jun, we examined whether a chimeric protein containing the amino-terminal half of c-Jun fused to the DNA-binding domain of GHF1, a pi- 
A

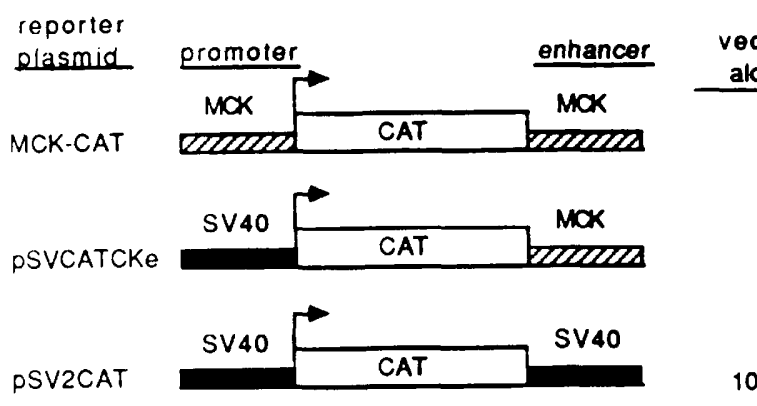

Enhancer mutants

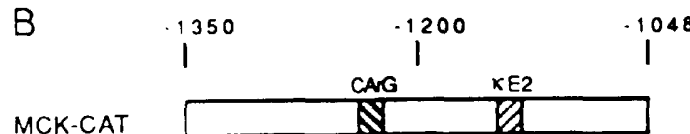

(wild-lype)

mut e6

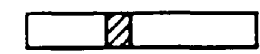

mut $\mathrm{CArG}$

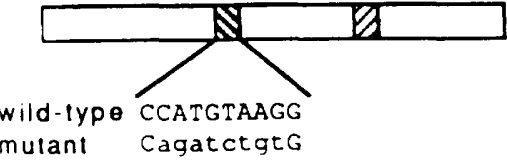

$100(62)$
Relative Irans-activation

vector myogenin

alone

1

10

100

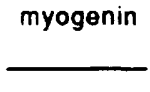

$100(100)$

$100(45)$

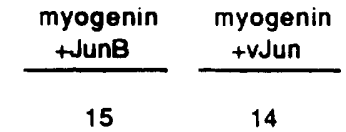

100

7

12

239

265

NT
1

13

Belative trans-activation

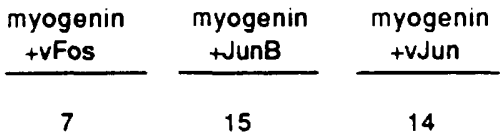

3

10

31

C
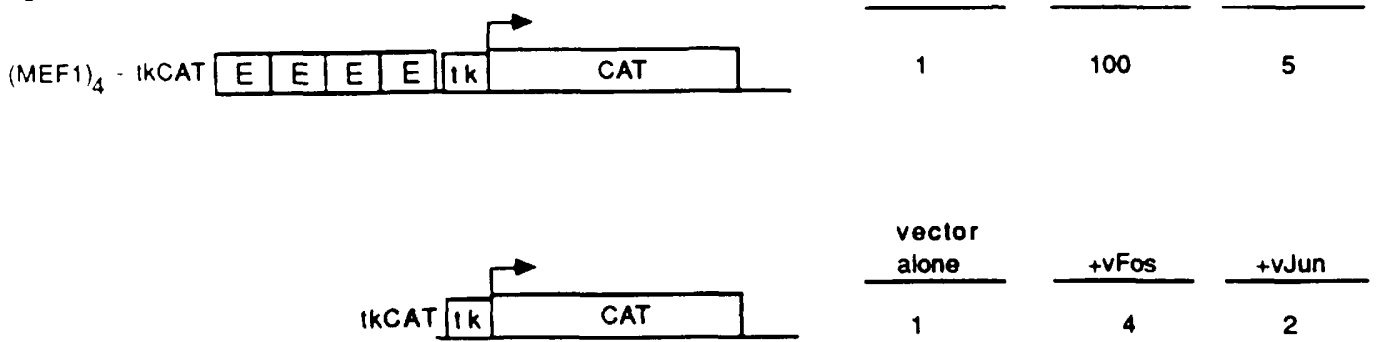

Figure 5. The E box in the MCK enhancer is the target for trans-repression by v-Fos, JunB, and v-Jun. 10T1/2 cells were transiently transfected with the indicated CAT vectors $(5 \mu \mathrm{g})$, EMSV-myogenin, or EMSV lacking a cDNA insert (vector alone), and expression vectors encoding v-Fos $(10 \mu \mathrm{g})$, JunB $(10 \mu \mathrm{g})$ or v-Jun $(10 \mu \mathrm{g})$ under control of the RSV-LTR, as indicated. Twenty-four hours after transfection, cultures were transferred from GM to DM and CAT activity was assayed in cell extracts $48 \mathrm{hr}$ later. (A) pSVCATCKe contains the SV40 promoter and MCK enhancer linked to CAT; pSV2CAT contains the SV40 promoter and SV40 enhancer linked to CAT. $(B \mid$ Wild-type and mutant MCK enhancers were inserted into the BamHI site of pCK246CAT, which contains the MCK basal promoter. Levels of expression of each reporter plasmid in the presence of myogenin relative to wild-type MCK-CAT are shown in parentheses. Values represent the average of at least two experiments. (NT) Not tested. $(C)(M E F 1)_{4}-$ tkCAT contains four copies of the MEF-1 site in front of the thymidine kinase promoter and tkCAT contains only the thymidine kinase promoter. Reporter plasmids were transfected with myogenin, v-Fos, JunB, and v-Jun expression vectors as indicated. Values for CAT activity are expressed relative to the level for each reporter plasmid in the presence of myogenin.

tuitary-specific transcription factor with a different DNA-binding site from Fos/Jun (Bodner et al. 1988), could repress activation by myogenin and MyoD. This chimera (c-Jun-GHF1) was an extremely efficient repressor of trans-activation by the myogenic regulators (Fig. 6A). Little or no inhibition was observed with GHF1 alone. We reproducibly observed that c-Jun-GHF1 was more potent than wild-type c-Jun in its ability to repress myogenin and MyoD. We believe the enhanced inhibitory activity of this chimera is the result of its longer half-life compared with that of c-Jun (B. Binetruy and T. Smeal, unpubl.). When equal amounts of c-Jun and c-Jun-GHF1 expression vectors were transfected into F9 cells, which lack endogenous c-Jun (Chiu et al. 1989; 


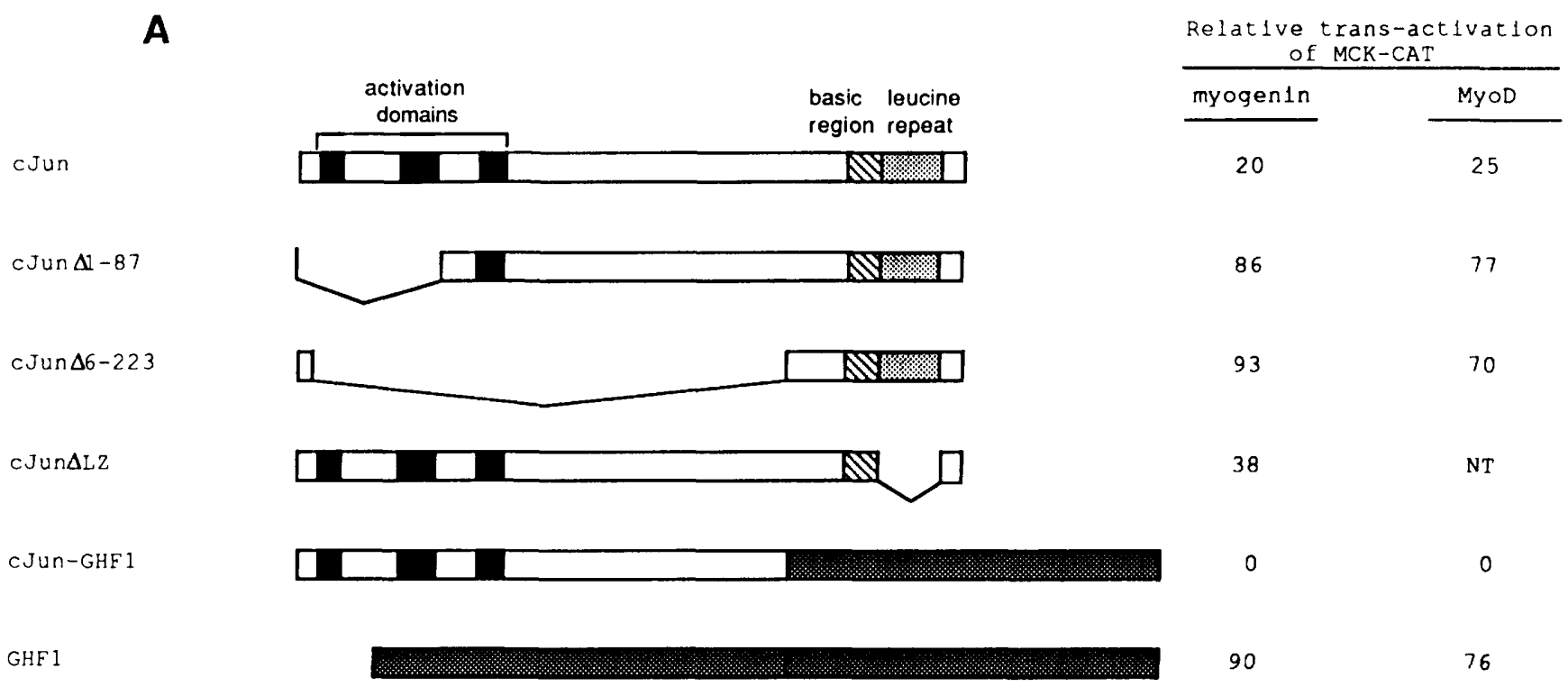

Figure 6. The amino-terminal region of c-Jun mediates repression of myogenin and MyoD. (A) 10T1/2 cells were transiently transfected with $4 \mu \mathrm{g}$ of MCK-CAT together with $5 \mu \mathrm{g}$ of EMSV-myogenin and $5 \mu \mathrm{g}$ of expression vectors encoding the indicated c-Jun mutants under control of the RSV-LTR. Schematic representations of the c-Jun mutants are shown: hatched boxes indicate DNA-binding domains; solid boxes indicate transcriptional activation regions; open boxes represent other sequences. Values for CAT activity are expressed relative to the level of expression in the presence of EMSV-myogenin or EMSV-MyoD and the RSV-LTR expression vector lacking a cDNA insert, which was set at $100 \%$. Values represent the average of multiple transfections. (NT) Not tested. (B) F9 cells were transiently transfected with expression vectors encoding c-Jun or c-Jun-GHFl or with an expression vector lacking a cDNA insert (control). Nuclear extracts were prepared $24 \mathrm{hr}$ later and analyzed for Jun expression using an anti-c-Jun antibodies raised against an amino-terminal peptide. The positions of c-Jun and c-Jun-GHFl are indicated at right.

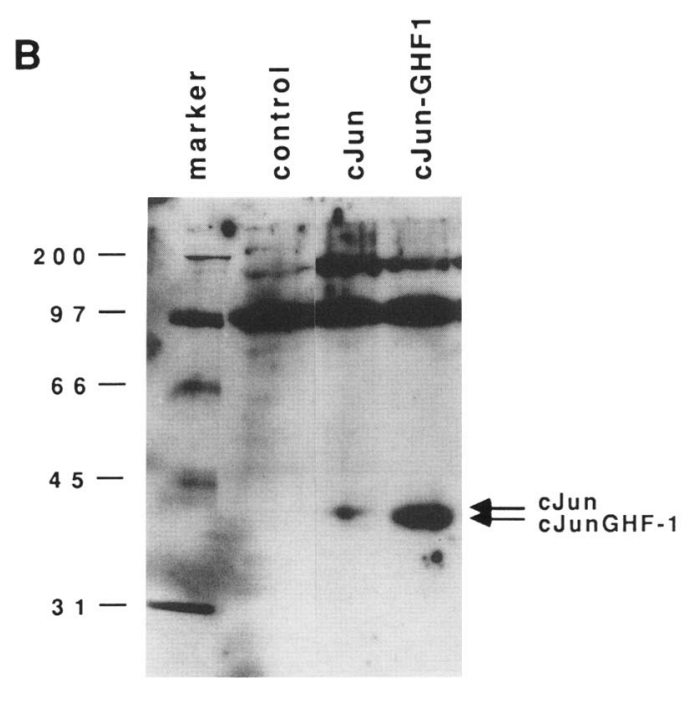

Yang-Yen et al. 1990a), the level of c-Jun-GHFl protein was $\sim 10$-fold higher than that of c-Jun protein, as tested by Western blot using antibody against the amino terminus of c-Jun (Fig. 6B).

To further investigate the ability of c-Jun-GHF1 to repress muscle-specific gene activation, we introduced the c-Jun-GHF1 expression vector with a hygromycinresistance gene stably into the myogenic cell line 10TFL2-3, which expresses myogenin constitutively (Brennan et al. 1991b). Whereas greater than half of the clones obtained with the hygromycin-resistance gene alone were able to terminally differentiate, there was almost no detectable differentiation of clones transfected with the c-Jun-GHF1 expression vector (Table 1). The amino terminus of c-Jun can therefore inhibit the transcription-activating functions of myogenin in transiently or stably transfected cells, indicating that c-JunGHF1 does not affect cell viability and that repression does not result simply from overexpression that may occur in transient assays.
Repression by Fos and lun is directed at the basic-HLH motif

The basic- $\mathrm{HLH}$ (bHLH) regions of myogenin and MyoD are required for DNA binding and collaborate with activation domains in the amino and carboxyl termini of these proteins to activate muscle-specific transcription (Brennan et al. 1991a; Weintraub et al. 1991; Schwarz et al, 1992). To determine whether trans-activation and sensitivity to trans-repression were mediated by separable domains, several deletion mutants of myogenin were tested for their responsiveness to Fos and Jun. As shown in Figure 7A, either the amino or carboxyl termini of myogenin could be deleted, with a partial loss in myogenic activity (mutants $\Delta N-$ myo and $\Delta C$-myo, respectively); deletion of the carboxyl terminus had a more dramatic effect on activity. The activity of both constructs was inhibited by Fos and Jun. However, if both the amino and carboxyl termini were deleted, leaving 
Table 1. Repression of myogenesis by stable transfection of c-Jun-GHF1

\begin{tabular}{lcc}
\hline Vector & $\begin{array}{l}\text { Hygromycin-resistant } \\
\text { clones (number) }\end{array}$ & $\begin{array}{l}\text { Myogenic } \\
\text { clones (\%) }\end{array}$ \\
\hline Control & 240 & 57 \\
c-Jun-GHF1 & 192 & 2 \\
\hline
\end{tabular}

The cell line 10TFL2-3 was stably transfected with a hygromycin-resistance gene alone (control) or with c-Jun-GHF1 as described in Materials and methods. Fourteen days after selection for hygromycin-resistance, plates were transferred to DM for 6 days. Colonies were then counted and the number containing multinucleate myotubes was determined.

just the bHLH region, all measurable myogenic activity was lost $(\Delta \mathrm{N} \Delta \mathrm{C}$-myo). Expression of the proteins encoded by each myogenin deletion mutant in transfected cells has been demonstrated (Schwarz et al. 1992). These results suggest that neither the amino- nor the carboxyterminal activation domains of myogenin are essential for sensitivity to trans-repression. Because the bHLH region alone $(\Delta \mathrm{N} \Delta \mathrm{C}$-myo) was inactive in the trans-activation assay, we could not assay the effects of Fos and Jun on that domain directly. We therefore used a chimera in which the acidic activation domain of the acidic coactivator VP16 was fused to the carboxyl terminus of the bHLH deletion mutant to test the responsiveness of this region to trans-repression. This chimera, called $\Delta \mathrm{N} \Delta \mathrm{C}$ VP16, was highly active against the $(\mathrm{MEF}-1\rangle_{4}-\mathrm{tkCAT}$ reporter and was repressed by v-Fos and c-Jun-GHF1 (Fig. $7 \mathrm{~B})$. The repression of $\Delta \mathrm{N} \Delta \mathrm{C}$-myo-VP16 by v-Fos and c-Jun-GHF1 was not the result of the squelching of the VP16 activation domain because a Gal4-VP16 chimera was insensitive to repression under this condition. Collectively, these results suggest that Jun and Fos interfere with the activity of the bHLH region of myogenin.

\section{Discussion}

Serum and peptide growth factors, such as FGF and TGF$\beta$, have been shown previously to suppress the activation of muscle-specific genes (for review, see Florini et al. 1991). Here, we show that (1) v-Fos, c-Fos, v-Jun, c-Jun, and JunB can mimic the inhibitory effects of growth factors on myogenesis and silence the transcriptional activating capacity of the muscle-specific activators myogenin and $\mathrm{MyoD} ;(2)$ the high-affinity $\mathrm{E}$ box within the MCK enhancer core is a target for trans-repression by Fos and Jun proteins; (3) amino-terminal sequences of c-Jun are sufficient for efficient inhibition of myogenin and MyoD activity; (4) the bHLH domain of myogenin appears to be the target for the repressive effects of Fos and Jun, (5) repression by Fos and Jun is a specific property of myogenic HLH proteins and is not observed with other bHLH proteins such as E47.

What types of mechanisms might account for the ability of Fos and Jun to block the actions of myogenin and MyoD? The amino terminus of c-Jun, which has the po- tential to repress myogenin and MyoD function, has been shown to contain a transcription activation domain (Angel et al. 1989). The requirement for an intact amino terminus for efficient repression of myogenin and MyoD activity by c-Jun is consistent with the notion that inhibition reflects competition for a limiting amount of a common target required for activation, a phenomenon known as squelching (Ptashne 1988). However, squelching through competition for a general transcription factor seems unlikely because neither Jun nor Fos interferes with expression of most other genes and transformation by Jun and Fos does not affect cell viability (Ball et al. 1988; Lassar et. al. 1989a; L. Li and E. Olson, unpubl.). That repression by Jun and Fos is not a general transcriptional response was demonstrated by their failure to inhibit trans-activation by E47, the lack of repression of the SV40 and thymidine kinase promoters, and the lack of inhibition of VP16. Thus, these findings support the idea that transcriptional interference by c-Jun is specific to the myogenic factors.

Although c- and v-Fos also repress the activity of myogenin and MyoD, repression by Fos may not occur through the same mechanism as for Jun. The lack of sequence similarity between Fos and Jun outside the DNA-binding and dimerization domain suggests that Fos may repress through a different mechanism than Jun. The absence of cooperativity between Fos and Jun in repression also suggests that repression by Fos does not involve the formation of a functional AP-1 complex.

Although our results suggest that the amino-terminal region of c-Jun may repress myogenin and MyoD activity through a mechanism involving competition for a limiting factor, they do not rule out the possibility that these early gene products could interact directly with myogenic HLH proteins to inhibit their activities in a manner analogous to the mechanism through which they repress glucocorticoid receptor (GCR) function (Diamond et al. 1990; Jonat et al. 1990; Schule et al. 1990; Yang-Yen et al. 1990b). In this regard, the bHLH of MyoD has recently been shown to interact directly with the leucine zipper of c-Jun (Bengal et al. 1992). Consistent with this mechanism for repression, we observed that deletion of the basic region and leucine zipper diminished the inhibitory activity of c-Jun. However, the observation that the leucine zipper-deficient protein c-Jun $\triangle \mathrm{LZ}$, which is incapable of repressing GCR function (Schule et al. 1990; Yang-Yen et al. 1990b), retains inhibitory activity, and that the c-Jun-GHF1 chimera can repress myogenin and $M y o D$, argues for two different mechanisms of transcriptional interference by c-Jun.

c-Jun and JunB both repress the activity of myogenin and $\mathrm{MyoD}$ but differ in their activities against AP-1-containing target genes. JunB inhibits transcriptional activation by c-Jun (Chiu et al. 1989). We have not yet mapped the sequences in JunB responsible for repression of muscle transcription. However, mapping of the sequences that account for the different abilities of $c$-Jun and JunB to activate AP-1 target genes indicates that the critical sequences reside within the basic region and leucine zipper. The amino-terminal activation domains of c-Jun and 
A

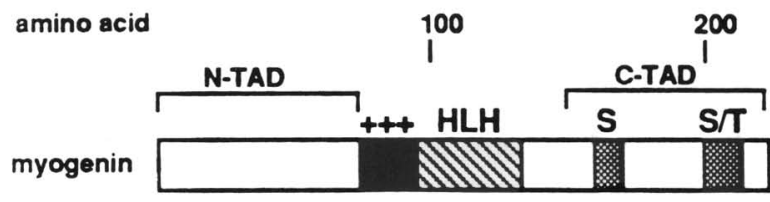

200

myogenin

$\Delta N$-myo

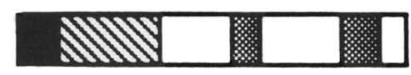

100

(59)

30

$\Delta \mathrm{C} \cdot \mathrm{myo}$

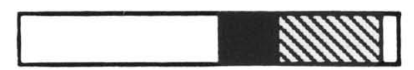

100

(20)

19

NT

$\Delta \mathbf{N} \Delta \mathbf{C} \cdot$ myo

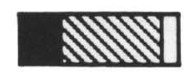

0

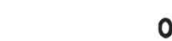

0

0

0

B
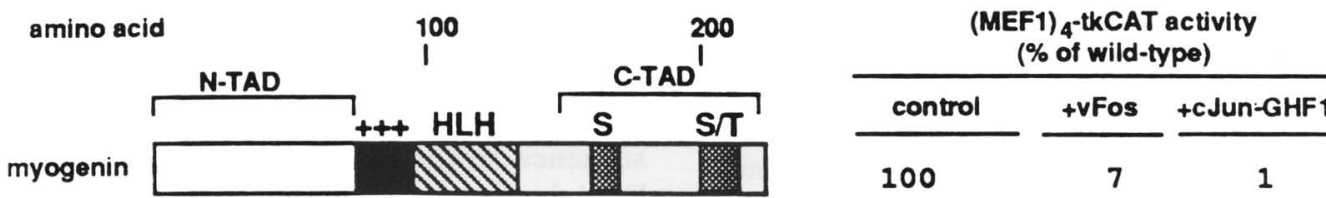

$\Delta N \Delta C$-myo -VP16

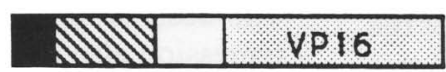

100

(333) 13

8

\section{GAL-VP16}

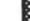

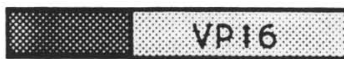

GAL

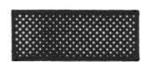

$<1$ NT $N T$

GAL4-CAT activity

$\frac{\text { control }}{100} \frac{+ \text { VFos }}{97} \frac{+ \text { cJun-GHF1 }}{112}$

Figure 7. The HLH domain of myogenin is the target for repression by v-Fos and c-Jun. (A) 10T1/2 cells were transiently transfected with $5 \mu \mathrm{g}$ of $(\mathrm{MEF} 1)_{4}$-tkCAT, $10 \mu \mathrm{g}$ of expression vectors encoding v-Fos, JunB, or c-Jun as specified, and $5 \mu \mathrm{g}$ of expression vectors encoding various myogenin mutants, except for mutant $\Delta \mathrm{C}$-myo, in which $10 \mu \mathrm{g}$ of the expression vector was used because of its low transcriptional activity. Twenty-four hours after transfection, cultures were transferred from GM to DM and CAT activity was assayed in cell extracts $48 \mathrm{hr}$ later. Values in parentheses denote the level of trans-activation of $(\mathrm{MEF}-1)_{4}-\mathrm{tkCAT}$ by the indicated mutant relative to wild-type myogenin. All other values are expressed relative to the maximum level of expression with each mutant, which was assigned a value of $100 \%,(B)$ The $10 \mathrm{~T} 1 / 2$ cells were transiently transfected with $5 \mu \mathrm{g}$ of $(\mathrm{MEF} 1)_{4}-\mathrm{tkCAT}$ or GAL4-CAT, $0.5 \mu \mathrm{g}$ of c-Jun-GHF1, and $5 \mu \mathrm{g}$ of expression vectors encoding myogenin, $\triangle \mathrm{N} \Delta \mathrm{C}$-myo-VP16, or GAL4-VP16 as described above. The level of expression of GAL4-CAT in the presence of GAL(1-147) is expressed relative to the level observed in the presence of GAL-VP16. Values represent the average of at least three experiments. (NT) Not tested. (N-TAD) Amino-terminal transcriptional activation domain; $(\mathrm{C}-\mathrm{TAD})$ carboxy-terminal transcriptional activation domain; $\{\mathrm{S})$ serine-rich region; $(\mathrm{S} / \mathrm{T})$ serine-, threonine-rich region; $(++)$ basic region.

JunB have very similar transcriptional activities (T. Deng and $M$. Karin, in prep.).

In contrast to c-Jun and JunB, which repressed musclespecific transcription and are induced by growth factors that inhibit myogenesis (Li et al. 1990), JunD had no effect on trans-activation by myogenin. The failure of
JunD to affect muscle-specific transcription is consistent with the observation that JunD is expressed constitutively in myoblasts and is not regulated during myoblast proliferation or differentiation ( $\mathrm{Li}$ et al. 1990). The inability of JunD to repress transcriptional activation by myogenin also supports the conclusion that the leucine 
zipper is not essential for this type of repression because JunD shows the same dimerization properties as c-Jun, $\mathrm{v}$-Jun, and JunB and would therefore be predicted to mimic their inhibitory activity if inhibition were mediated solely by the leucine zipper.

c-Jun and JunD contain segments with high homology and regions of divergence within their amino termini. The failure of JunD to repress myogenin efficiently suggests that its divergence in the amino terminus precludes repression, perhaps by mediating protein-protein interactions distinct from those of c-Jun. JunD is also incapable of activating an AP-1-dependent reporter (Yang-Yen et al. 1990a). JunD also fails to inhibit estrogen receptor activity, whereas c-Jun and JunB are potent repressors of the estrogen receptor. Repression of estrogen receptor activity by c-Jun has been mapped to a region within the amino terminus (Doucas et al. 1991). Overexpression of JunD also has no effect on cell growth, whereas c-Jun, and to a lesser extent JunB, can induce cellular transformation (Castellazzi et al. 1991). Analysis of c-Jun deletion mutants has shown that the aminoterminal portion (amino acids 2-168) is required for transformation (Alani et al. 1991) and that the DNAbinding and dimerization sequences of c-Jun can be replaced with those of JunD without a loss in transforming activity (Castellazzi et al. 1991). Therefore, in different biological events, members of the Jun family can function differently. For instance, JunB demonstrates effects on myogenin similar to that of c-Jun, even though JunB has been shown to be a negative regulator of c-Jun /Chiu et al. 1989).

The observation that repression by Fos and Jun is targeted at the bHLH region, which itself lacks the potential to activate transcription (Schwarz et al. 1992), suggests that these proteins may compete for interaction with a third factor that normally interacts with the bHLH region to activate muscle-specific transcription. Such a factor would presumably be specific for the myogenic bHLH because transcriptional activation by E47 was insensitive to repression by Fos and Jun. In this regard, the basic regions of myogenin and MyoD contain a conserved recognition sequence that has been proposed to interact with a coregulator to induce muscle transcription (Davis et al. 1990; Brennan et al. 1991; Weintraub et al. 1991b). Mutagenesis studies suggest that such a coregulator would not recognize the basic regions of E2A proteins and would not be essential for transcriptional activation by this class of bHLH proteins. Experiments are under way to determine whether the amino terminus of c-Jun interacts with proteins from myotube nuclear extracts that may fulfill the criteria of such a coregulator.

It is conceivable that Fos or Jun could induce the expression of an inhibitory factor that suppresses musclespecific transcription, but this type of mechanism seems less likely to explain repression by c-Jun because replacement of the DNA-binding domain of c-Jun with the corresponding domain of GHF1, a pituitary-specific transcription factor with an entirely different sequence specificity (Bodner et al. 1988), does not impair its ability to inhibit myogenin and MyoD activity. The c-Jun-GHF1 chimera is unlikely to activate the same set of target genes as Jun and Fos. Because this chimera is unable to induce transformation (Alani et al. 1991), we can also conclude that repression of myogenin and MyoD function is not an indirect consequence of deregulated growth control associated with transformation.

The HLH protein Id, which is expressed at high levels in proliferating cells maintained in mitogen-rich medium and is down-regulated during myogenesis, has been proposed as a potential mediator of the effects of growth signals on myogenesis. Id lacks a basic region and can inhibit DNA binding of other HLH proteins such as E12, E47, and MyoD (Benezra et al. 1990). Because Id dimerizes preferentially with E2A products, Fos and Jun would be expected to repress trans-activation by E47 if they acted through an Id-mediated mechanism. However, our results show clearly that transcriptional repression by Fos and Jun is specific for myogenic HLH proteins and is not observed with E47. Further evidence against a role for Id in repression by $\mathrm{v}$-Fos has recently been obtained through analysis of v-Fos-transformed myoblasts, which down-regulate Id normally upon withdrawal of serum (L. $\mathrm{Li}$ and E. Olson, unpubl.).

What is the biological significance of the transcriptional repression mediated by the amino terminus of c-Jun? Although these studies have primarily involved transient transfection assays, the finding that expression of c-Jun-GHF1 together with myogenin in stably transfected cells is sufficient to block activation of musclespecific genes shows that repression by c-Jun can occur at physiological levels of expression and is not restricted to transient transfection assays in which proteins may be expressed at abnormally high levels. A variety of growthrelated signaling pathways initiated at the cell membrane lead to the induction of c-Fos, c-Jun, and JunB (Karin 1990). It is possible that these gene products accumulate in nuclei in response to growth factor signals and thereby inhibit myogenic differentiation. The possibility that growth factor-inducible early gene products, such as Fos and Jun, might mediate the inhibitory actions of growth factors on the muscle differentiation program was initially suggested by the observation that protein synthesis is required for serum and FGF to repress muscle-specific gene expression (Spizz et al. 1986). Signal transduction pathways that involve H-Ras (Imler et al. 1988; Binetruy et al. 1991), protein kinase C (Angel et al. 1987, 1988b; Lee et al. 1987; Boyle et al. 1991), and cAMP-dependent protein kinase (Chiu et al. 1989), each of which have been implicated in negative regulation of myogenesis (Lin et al. 1987; Olson et al. 1987; Hu and Olson 1988; Lassar et al. 1989a; Vaidya et al. 1991), lead to induction and activation of Fos and Jun proteins. Thus, it is conceivable that Fos and Jun could act as final mediators for diverse signals that inhibit myogenesis.

Finally, it is intriguing that the decision of a myoblast to proliferate or differentiate seems to be determined by a balance between growth factor-generated signals and differentiation signals mediated by myogenic HLH proteins. Our results and those of others (Lassar et al. 1989a; 
Bengal et al. 1992) support the notion that repression of myogenin or MyoD function by Fos and Jun is a titratable phenomenon that depends on the ratio of these proteins. Considering that the bHLH region is required for growth inhibition by MyoD (Crescenzi et al. 1990; Sorrentino et al. 1990) and for sensitivity of myogenin to inhibition by Fos and Jun, it is tempting to speculate that antagonism between growth and differentiation in this system may reflect convergence of these regulatory pathways at a common point possibly involving a third factor that interacts with the myogenic bHLH.

\section{Materials and methods}

\section{Cell culture and transfections}

C3H10T1/2 cells were cultured in Dulbecco's modified Eagle medium (DMEM) with $20 \%$ fetal bovine serum (FBS) as described previously (Edmondson and Olson 1989). To initiate differentiation, growth medium (GM) was replaced with DMEM containing $2 \%$ horse serum (differentiation medium, DM). For transfections, cells were plated on $10-\mathrm{cm}$ dishes at a density of $5 \times 10^{5}$ cells per dish in GM. Twenty-four hours later, cultures were refed with $4 \mathrm{ml}$ of GM for $2 \mathrm{hr}$ before transfection. Calcium phosphate precipitates were prepared as described previously (Sternberg et al. 1988). Forty-eight hours after transfection, cells were harvested and CAT activity was determined in aliquots of cell extracts containing equivalent quantities of protein. To account for possible nonspecific effects of variable amounts of DNA in the transfection assays, the amount of DNA in all transfections was made equivalent by addition of pUC19 or expression vector lacking a cDNA insert.

The 10TFL2-3 cell line was derived from 10T1/2 cells by stable transfection of EMSV-myogenin and a neomycin-resistance gene (Brennan et al. 1991b). These cells were stably transfected with $50 \mathrm{ng}$ of a hygromycin-resistance gene alone or with $2 \mu \mathrm{g}$ of the c-Jun-GHF1 expression vector, and hygromycin-resistant clones were selected as described previously (Sternberg et al. 1988).

The MCK-CAT reporter genes used for transfections have been described previously (Sternberg et al. 1988). Briefly, MCKCAT, referred to previously as pCKCATe $4+$, contains the region $-1350 /-1048$ upstream of mck inserted into the BamHI site $3^{\prime}$ of pCK246CAT, which contains the 246-bp mck promoter immediately upstream of CAT. pCKCATe $6+$ contains the region $-1204 /-1048$ of $m c k$ inserted in the BamHI site of pCK246CAT. pCKCATmutCArG is a derivative of pCKCATe + in which the CArG motif was mutated from CCATGTAAGGAG to CAGATCTGTGGA. pSVCATMCKe contains the SV40 promoter and the mck enhancer, whereas pCKCATSVe contains the mck promoter and the SV40 enhancer. (MEF-1 $)_{4}$-tkCAT, also known as $4 \mathrm{R}-\mathrm{tkCAT}$, contains four copies of the MEF-1 site from the MCK enhancer immediately upstream of the thymidine kinase basal promoter linked to CAT (Weintraub et al. 1990).

Reporter plasmids were cotransfected with the expression vector pEMSVscribe (EMSV) (Davis et al. 1987), which contains the MSV-LTR, with or without a myogenin or MyoD cDNA insert, as specified. The following expression vectors were tested for their effects on the trans-activating capacity of myogenin. FBJ-2 contains the $\mathrm{v}$-fos-coding sequence under transcriptional control of the viral LTR (van Beveren et al. 1983). c-foscoding sequences were under control of the SV40 promoter and enhancer. $\Delta$-Fos is a derivative of c-fos that contains a frameshift mutation in the open reading frame (Schonthal et al. 1988). c-jun, c-jun(mut), junB (Ryder et al. 1988b), and junD (Li et al. 1990) cDNAs were linked to the RSV-LTR (Angel et al. 1988). The deletion mutants of c-Jun and the chimeras with GHFl are described in Angel et al. (1989). These mutants are expressed under the control of the RSV-LTR. c-Jun $\Delta$ LZ (Schule et al. 1990), also under control of the RSV-LTR, was kindly provided by I. Verma.

The expression plasmid for expression of E2-5 (E47) was pSVE2-5, described previously (Henthorn et al. 1990). The reporter plasmid $(\mathrm{E} 2+5)_{4}$-TATA-CAT contains four copies each of the $\mu \mathrm{E} 2$ and $\mu \mathrm{E} 5$ sites linked to the alkaline phosphatase TATA box (Henthorn et al. 1990).

The activator GAL-VP16 contains the VP16-activating region fused in-frame to amino acids 1-147 of GAL4 in the plasmid pSG424, which contains the SV40 promoter and enhancer (Lillie et al. 1989). The GAL4 reporter plasmid was pG5ElbCAT and contains five copies of the GAL4-responsive element (Lillie et al. 1989).

\section{Generation of mutants}

Mutagenesis of the mck enhancer and myogenin was performed on single-stranded templates as described previously (Brennan et al. 1991a). All mutations were confirmed by sequencing, and the mutagenic regions were subcloned into wild-type vectors to avoid extraneous mutations outside the mutagenic region. Myogenin deletion mutants and VP16 chimeras have been described elsewhere (Schwarz et al. 1992). Briefly, $\Delta \mathrm{N}$-myo was created by introducing an in-frame deletion of amino acids 4-79. $\Delta \mathrm{C}$-myo was created by introduction of a stop codon at amino acid 138. $\Delta \mathrm{N} \Delta \mathrm{C}$-myo is a combination of $\Delta \mathrm{N}$-myo and $\Delta \mathrm{C}$-myo and contains residues $1-3$ fused in-frame to residues 80-137. $\Delta \mathrm{N} \Delta \mathrm{C}$-myo-VP16 was created by ligation of a SallBamHI fragment of VP16, which contains the activating region, to the NcoI site (codon 156 ) of $\Delta \mathrm{N}$-myo. All deletion mutants were confirmed by DNA sequencing.

\section{Western blot analysis}

For analysis of expression of c-Jun and c-Jun-GHF1, F9 cells were transiently transfected with the corresponding expression vectors, nuclear extracts were prepared $24 \mathrm{hr}$ later, and c-Jun protein was detected by Western blot using an antibody directed specifically against the amino terminus of c-Jun (Binetruy et al. 1991).

\section{Acknowledgments}

We are grateful to $S$. Jasser and J. Toma for technical assistance, B. Binetruy for analysis of c-Jun and c-Jun-GHF1 expression, E. Madson for secretarial assistance, M. Perry, B. Klein, M. Schneider, and members of the Olson laboratory for comments on the manuscript. We thank $\mathrm{H}$. Weintraub and I. Verma for sharing information prior to publication and E. Sternberg, T. Brennan, T. Chakraborty, and J. Martin for providing mutants of myogenin and the MCK enhancer. We also thank the following individuals for important reagents: D. Nathans (junB), C. Murre (E12), T. Curran (c-fos), A. Schonthal ( $\Delta f o s)$, A. Lassar and H. Weintraub [(MEF-1 $)_{4}-$ tkCAT and MyoD], I. Verma (c-Jun $\left.\Delta \mathrm{LZ}\right)$, T. Kadesch [pSVE2 -5 and $(E 2+5)_{4}-$ TATA-CAT], and $M$. Green (pSG424 and pG5E1bCAT). This work was supported by grants from the National Institutes of Health (NIH) and the American Cancer Society to E.N.O. and grants from the NIH and the Environmental Protection Agency to M.K. E.N.O. is an Established Investigator of the American Heart Association. 
L.L. is a Rosalie B. Hite predoctoral fellow. J.C.C was supported by a Fogarty International Postdoctoral Fellowship from the NIH.

The publication costs of this article were defrayed in part by payment of page charges. This article must therefore be hereby marked "advertisement" in accordance with 18 USC section 1734 solely to indicate this fact.

\section{References}

Alani, R., P. Brown, B. Binetruy, H. Dosaka, R.K. Rosenberg, P. Angel, M. Karin, and M.J. Birrer. 1991. The transactivating function of the c-Jun proto-oncoprotein is required for cotransformation of rat embryo cells. Mol. Cell. Biol. 11: 6286-6295.

Angel, P., M. Imagawa, R. Chiu, B. Stein, R.J. Imbra, H.J. Rahmsdorf, C. Jonat, P. Herrlich, and M. Karin. 1987. Phorbol ester-inducible genes contain a common cis element recognized by a TPA-modulated trans-acting factor. Cell 49: 729-739.

Angel, P., K. Hattori, T. Smeal, and M. Karin. 1988a. The jun proto-oncogene is positively autoregulated by its product, Jun/AP-1. Cell 55: 875-885.

Angel, P., E.A. Allegretto, S. Okino, K. Hattori, W.J. Boyle, T. Hunter, and M. Karin. 1988b. Oncogene iun encodes a sequence-specific trans-activator similar to AP-1. Nature 332: $166-171$.

Angel, P., T. Smeal, J. Meek, and M. Karin. 1989. Jun and v-Jun contain multiple regions that participate in transcriptional activation in an interdependent manner. New Biologist 1: 35-43.

Ball, A.R., Jr., T.J. Bos, C. Loliger, L.P. Nagata, T. Nishimura H. Su, H. Tsuchie, and P.K. Vogt. 1988. jun: Oncogene and transcriptional regulator. Cold Spring Harbor Symp. Quant. Biol. 53: 687-693.

Benezra, R., R.L. Davis, D. Lockshon, D.L. Turner, and H. Weintraub. 1990. The protein Id: A negative regulator of helixloop-helix DNA binding proteins. Cell 61: 49-59.

Bengal, E., L. Ransone, R. Scharfmann, V.J. Dwarki, S.J. Tapscott, H. Weintraub, and I.M. Verma. 1992. Functional antagonism between c-Jun and MyoD proteins: A direct physical association. Cell 68: 507-519.

Binetruy, B., T. Smeal, and M. Karin. 1991. Ha-Ras augments c-Jun activity and stimulates phosphorylation of its activation domain. Nature 351: 122-127.

Bodner, M., J.L. Castrillo, L.E. Theill, T. Deerinck, M. Ellisman, and $M$. Karin. 1988. The pituitary specific transcription factor GHF-1 is a homeobox-containing protein. Cell 55: 505518.

Bohmann, D., T. Bos, A. Admon, T. Nishimura, P. Vogt, and R. Tjian. 1987. Human proto-oncogene c-jun encodes a DNA binding protein with structural and functional properties of transcription factor AP-1. Science 238: 1386-1392.

Boyle, W.J., T. Smeal, L.H.K. Defize, P. Angel, J.R. Woodgett, M. Karin, and T. Hunter. 1991. Activation of protein kinase C decreases phosphorylation of c-Jun at sites that negatively regulate its DNA-binding activity. Cell 64: 573-584.

Braun, T., G. Buschhausen-Denker, E. Bober, E. Tannich, and H.H. Arnold. 1989. A novel human muscle factor related to but distinct from MyoDl induces myogenic conversion in 10T1/2 fibroblasts. EMBO I. 8: 701-709.

Brennan, T., D.G. Edmondson, L. Li, and E.N. Olson. 1991b. TGF- $\beta$ represses the actions of myogenin through a mechanism independent of DNA binding. Proc. Natl. Acad. Sci. 88: 3822-3826.
Brennan, T.J. and E.N. Olson. 1990. Myogenin resides in the nucleus and acquires high affinity for a conserved enhancer element on heterodimerization. Genes \& Dev. 4: 582-595.

Brennan, T.J., T. Chakraborty, and E.N. Olson. 1991a. Mutagenesis of the myogenin basic region identifies an ancient protein motif critical for activation of myogenesis. Proc. Natl. Acad. Sci. 88: 5675-5679.

Buskin, J.N., and S.D. Hauschka. 1989. Identification of a myocyte-specific nuclear factor which binds to the muscle-specific enhancer of the mouse muscle creatine kinase gene. Mol. Cell. Biol. 9: 2627-2640.

Castellazzi, M., G. Spyrou, N. La Vista, J.-P. Dangy, F. Piu, M. Yaniv, and G. Brun. 1991. Overexpression of c-jun, junB, or junD affects cell growth differently. Proc. Natl. Acad. Sci. 88: 8890-8894.

Chakraborty, T., T.J. Brennan, and E.N. Olson. 1991. Differential trans-activation of a muscle-specific enhancer by myogenic helix-loop-helix proteins is separable from DNA binding. J. Biol. Chem. 266: 2878-2882.

Chiu, R., W.J. Boyle, J. Meek, T. Smeal, T. Hunter, and M. Karin. 1988. The c-Fos protein interacts with c-Jun/AP-1 to stimulate transcription of AP-1 responsiveness genes. Cell 54: 541-522.

Chiu, R., P. Angel, and M. Karin. 1989. Jun-B differs in its biological properties from, and is a negative regulator of $\mathrm{c}$-Jun. Cell 59: 979-986.

Crescenzi, M., T.P. Fleming, A.B. Lassar, H. Weintraub, and S.A. Aaronson. 1990. MyoD induces growth arrest independent of differentiation in normal and transformed cells. Proc. Natl. Acad. Sci. 87: 8442-8446.

Davis, R.L., H. Weintraub, and A.B. Lassar. 1987. Expression of a single transfected cDNA converts fibroblasts to myoblasts. Cell 51: 987-1000.

Davis, R.L., P.-F. Cheng, A.B. Lassar, and H. Weintraub. 1990. The MyoD DNA binding domain contains a recognition code for muscle-specific gene activation. Cell 60: 733-746.

Diamond, M.I., J.M. Miner, S.K. Hoshinaga, and K.R. Yamamoto. 1990. Transcription factor interactions: Selectors of positive or negative regulation from a single DNA element. Science 249: 1266-1272.

Doucas, V., G. Spyrou, and M. Yaniv. 1991. Unregulated expression of c-Jun of c-Fos proteins but not JunD inhibits estrogen receptor activity in human breast cancer derived cells. EMBO I. 10: 2237-2245.

Edmondson, D. and E.N. Olson. 1989. A gene with homology to the myc similarity region of $\mathrm{MyoDl}$ is expressed during myogenesis and is sufficient to activate the muscle differentiation program. Genes \& Dev. 3: 628-640.

Falcone, G., F. Tato, and S. Alema. 1985. Distinctive effects of the viral oncogenes myc, erb, fps, and src on the differentiation program of quail myogenic cells. Proc. Natl. Acad. Sci. 82: $426-430$.

Florini, J.R., D.Z. Ewton, and K.A. Magri. 1991. Hormones, growth factors and myogenic differentiation. Annu. Rev. Physiol. 53: 201-216.

Gossett, L. A., D. J. Kelvin, E. A. Sternberg, and E. N. Olson. 1989. A new myocyte-specific enhancer-binding factor that recognizes a conserved element associated with multiple muscle-specific genes. Mol. Cell. Biol. 9: 5022-5033.

Henthorn, P., M. Kildejian, and T. Kadesch. 1990. Two distinct transcription factors that bind the immunoglobulin enhancer $\mu \mathrm{E} 5 / \mathrm{kE} 2$ motif. Science 247: 467-470.

$\mathrm{Hu}$, J.S. and E.N. Olson. 1988. Inhibition of differentiation of the $\mathrm{BC}_{3} \mathrm{Hl}$ muscle cell line through cAMP-dependent and -independent pathways. J. Biol. Chem. 263: 19670-19677.

Imagawa, M., R. Chiu, and M. Karin. 1987. Transcription factor 
AP-2 mediates induction by two different signal-transduction pathways: Protein kinase C and cAMP. Cell 51: 251260.

Imler, J., C. Schatz, C. Wasylyk, B. Chatton, and B. Wasylyk. 1988. A Harvey-ras responsiveness transcription element is also responsive to a tumour-promoter and to serum. Nature 332: $275-278$.

Jaynes, J.B., J.B. Johnson, J.M. Buskin, C.L. Gartside, and S.D. Hauschka. 1988. The muscle creatine kinase gene is regulated by multiple elements, including a muscle-specific enhancer. Mol. Cell. Biol. 6: 2855-2864.

Jonat, C., H.J. Rahmsdorf, K.-K. Park, A.C.B. Cato, S. Gebel, H. Ponta, and P. Herrlich. 1990. Antitumor promotion and antiinflammation: Down-modulation of AP-1 (Fos/Jun) activity by glucocorticoid hormone. Cell 62: 1189-1204.

Karin, M. 1990. The AP-1 complex and its role in transcriptional control by protein kinase C. In Molecular aspects of cellular regulation. (ed. P. Cohen and J.G. Foulkes), vol. 6 pp. 143161. Elsevier Science Publishers, Amsterdam.

Konig, H., H. Ponta, U. Rahmsdorf, M. Buscher, A. Schonthal, H.J. Rahmsdorf, and P. Herrlich. 1989. Autoregulation of fos: The dyad symmetry element as the major target of repression. $E M B O$ J. 8: 2559-2566.

Lassar, A.B., M.J. Thayer, R.W. Overell, and H. Weintraub. 1989a. Transformation by activated RAS or FOS prevents myogenesis by inhibiting expression of MyoDl. Cell 58: 659-667.

Lassar, A.B., J.N. Buskin, D. Lockshon, R.L. Davis, S. Apone, S.D. Hauschka, and H. Weintraub. $1989 \mathrm{~b}$. MyoD is a sequence-specific DNA binding protein requiring a region of myc homology to bind to the muscle creatine kinase enhancer. Cell 58: 823-831.

Lassar, A.B., R.L. Davis, W.E. Wright, T. Kadesch, C. Murre, A. Voronova, D. Baltimore, and H. Weintraub. 1991. Functional activity of myogenic HLH proteins requires heterooligomerization with E12/E47-like proteins in vivo. Cell 66: 305-315.

Lee, W., P. Mitchell, and R. Tjian. 1987. Purified transcription factor AP-1 interacts with TPA-inducible enhancer elements. Cell 49: 741-752.

Li, L., J.S. Hu, and E.N. Olson. 1990. Different members of the jun family exhibit distinct patterns of expression in response to type $\beta$ transforming growth factor. I. Biol. Chem. 265: 1556-1562.

Lillie, J.W. and M.R Green. 1989. Transcription activation by adenovirus Ela protein. Nature 338: 39-44.

Lin, Z., J.R. Eshelman, S. Forry-Schaudies, S. Duran, J.L. Lessard, and H. Holtzer. 1987. Sequential disassembly of myofibrils induced by myristate acetate in cultured myotubes. J. Cell Biol. 105: 1365-1376.

Miner, J.H. and B.J. Wold. 1991. c-myc inhibition of MyoD and myogenin-initiated myogenic differentiation. Mol. Cell. Biol. 11: 2842-2851.

Minty, A. and L. Kedes. 1986. Upstream regions of the human cardiac actin gene that modulate its transcription in muscle cells: Presence of an evolutionarily conserved repeated motif. Mol. Cell. Biol. 6: 2125-2136.

Murre, C., P.S. McCaw, H. Vaessin, M. Caudy, L.Y. Jan, Y.N. Jan, C.V. Cabrera, J.N. Buskin, S.D. Hauschka, A.B. Lassar, H. Weintraub, and D. Baltimore. 1989. Interactions between heterologous helix-loop-helix proteins generate complexes that bind specifically to a common DNA sequence. Cell 58: $537-544$.

Olson, E.N. 1990. MyoD family: A paradigm for development? Genes \& Dev. 4: 1454-1461.

Olson, E.N., G. Spizz, and M. Tainsky. 1987. The oncogenic forms of $\mathrm{N}$-ras or $\mathrm{H}$-ras prevent skeletal myoblast differen- tiation. Mol. Cell Biol. 7: 2104-2111.

Piette, J. and M. Yaniv. 1987. Two different factors bind to the $\alpha$-domain of the polyoma virus enhancer, one of which also interacts with the SV40 and c-fos enhancers. EMBO $I$. 6: 1331-1337.

Ptashne, M. 1988. How eucaryotic transcriptional activators work. Nature 335: 683-689.

Rhodes, S.J. and S.F. Konieczny. 1989. Identification of MRF4: A new member of the muscle regulatory factor gene family. Genes \& Dev. 3: 2050-2061.

Ryder, K., L.F. Lau, and D. Nathans. 1988. A gene activated by growth factors is related to the oncogene v-jun. Proc. Natl. Acad. Sci. 85: 1487-1491.

Ryder, K., A. Lanahan, E. Perez-Albuerne, and D. Nathans. 1989. Jun-D: A third member of the Iun gene family. Proc. Natl. Acad. Sci. 86: 1500-1503.

Schneider, M.D., M.B. Perryman, P.A. Payne, G. Spizz, R. Roberts, and E.N. Olson. 1987. Autonomous expression of c-myc in $\mathrm{BC}_{3} \mathrm{Hl}$ cells partially inhibits but does not prevent myogenic differentiation. Mol. Cell. Biol. 7: 1973-1977.

Schonthal, A., P. Herrlich, H.J. Rahmsdorf, and H. Ponta. 1988. Requirement for fos gene expression in the transcriptional activation of collagenase by other oncogenes and phorbol esters. Cell 54: 325-334.

Schule, R., P. Rangarajan, S. Kliewer, L.J. Ransone, J. Bolado, N. Yang, I.M. Verma, and R.M. Evans. 1990. Functional antagonism between oncoprotein c-Jun and glucocorticoid receptor. Cell 62: 1217-1226.

Schwarz, J., T. Chakraborty, J. Martin, J. Zhou, and E. N. Olson. 1992. The basic region of myogenin cooperates with two transcription activation domains to induce muscle-specific transcription. Mol. Cell. Biol. 12: 266-275.

Sorrentino, V., R. Pepperkok, R.L. Davis, W. Ansorge, and L. Philipson. 1990. Cell proliferation inhibited by MyoDl independently of myogenic differentiation. Nature 345: 813815 .

Spizz, G., D. Roman, A. Strauss, and E.N. Olson. 1986. Serum and fibroblast growth factor inhibit myogenic differentiation through a mechanism dependent on protein synthesis and independent of cell proliferation. I. Biol. Chem. 261: 94839488.

Sternberg, E., G. Spizz, M. Perry, D. Vizard,T. Weil, and E.N. Olson. 1988. Identification of upstream and intragenic elements that confer cell type-restricted and differentiationspecific expression of the muscle creatine kinase gene. Mol. Cell Biol. 8: 2806-2909.

Tooze, J. 1980. DNA of tumor viruses, 2nd ed. Cold Spring Harbor Laboratory, Cold Spring Harbor, New York.

Vaidya, T.B., S.J. Rhodes, E.J. Taparowsky, and S.F. Konieczny. 1989. Fibroblast growth factor and transforming growth factor $\beta$ repress transcription of the myogenic regulatory gene MyoDl. Mol. Cell. Biol. 9: 3576-3579.

Vaidya, T.B., C.M. Weyman, D. Teegarden, C.L. Ashendel, and E.J. Taparowsky. 1991. Inhibition of myogenesis by the H-ras oncogene: Implication of a role for protein kinase C. I. Cell Biol. 114: 809-820.

Van Beveren, C., F. van Straaten, T. Curran, R. Muller, and I.M. Verma. 1983. Analysis of FBJ-MuSV provirus and c-fos (mouse) gene reveals that viral and cellular fos gene products have different carboxy termini. Cell 32: 1241-1255.

Weintraub, H., R. Davis, D. Lockshon, and A. Lassar. 1990. MyoD binds cooperatively to two sites in a target enhancer sequence: Occupancy of two sites is required for activation. Proc. Natl. Acad. Sci. 87: 5623-5627.

Weintraub, H., R. Davis, S. Tapscott, M. Thayer, M. Krause, R. Benezra, T. Blackwell, D. Turner, R. Rupp, S. Hollenberg, Y. 
Zhuang, and A. Lassar. 1991a. The myoD gene family: Nodal point during specification of the muscle cell lineage. Science 251: 761-766.

Weintraub, H., V.J. Dwarki, I. Verma, R. Davis, S. Hollenberg, L. Snider, A. Lassar, and S.J. Tapscott. 1991b. Muscle-specific transcriptional activation by MyoD. Genes \& Dev. 5: 13771386.

Wright, W.E., D.A. Sassoon, and V.K. Lin. 1989. Myogenin, a factor regulating myogenesis, has a domain homologous to MyoD. Cell 56: 607-617.

Yang-Yen, H.-F., R. Chiu, and M. Karin. 1990a. Elevation of AP-1 activity during F9 cell differentiation is due to increased c-jun transcription. New Biologist 2: 351-361.

Yang-Yen, H.-F., J.-C. Chambard, Y.-L. Sun, T. Smeal, T.J. Schmidt, J. Drouin, and M. Karin. 1990b. Transcriptional interference between c-Jun and the glucocorticoid receptor: Mutual inhibition of DNA binding due to direct proteinprotein interaction. Cell 62: 1205-1215. 


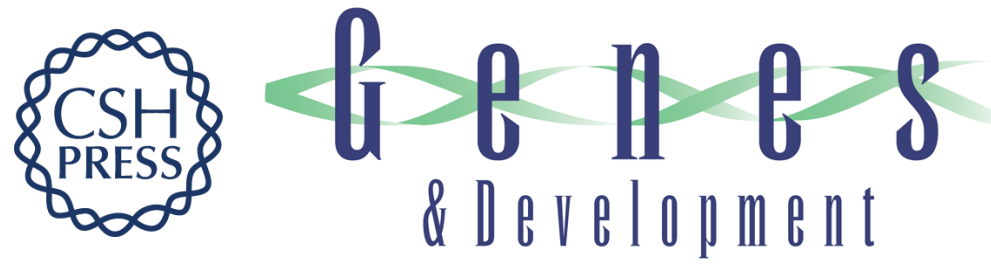

\section{Fos and Jun repress transcriptional activation by myogenin and MyoD: the amino terminus of Jun can mediate repression.}

L Li, J C Chambard, M Karin, et al.

Genes Dev. 1992, 6:

Access the most recent version at doi:10.1101/gad.6.4.676

References This article cites 70 articles, 33 of which can be accessed free at:

http://genesdev.cshlp.org/content/6/4/676.full.html\#ref-list-1

License

Email Alerting

Service

Receive free email alerts when new articles cite this article - sign up in the box at the top right corner of the article or click here.

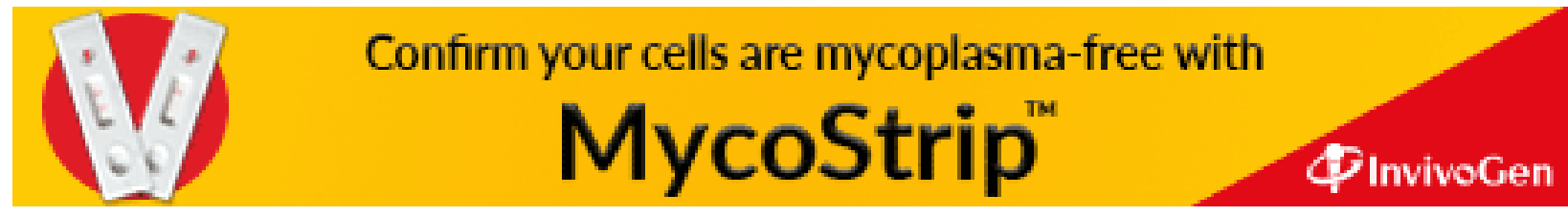

